\title{
$\begin{array}{r}\text { WAGENINGEN } \\ \hline\end{array}$
}

\section{Revamping the metaphysics of Ethnobiological classification}

\author{
Ludwig, D.
}

This is a "Post-Print" accepted manuscript, which has been published in "Current Anthropology"

This version is distributed under a non-commercial no derivatives Creative Commons (c) (1) $(9)$

(CC-BY-NC-ND) user license, which permits use, distribution, and reproduction in any medium, provided the original work is properly cited and not used for commercial purposes. Further, the restriction applies that if you remix, transform, or build upon the material, you may not distribute the modified material.

Please cite this publication as follows:

Ludwig, D. (2018). Revamping the metaphysics of Ethnobiological classification. Current Anthropology, 59(4), 415-438. DOI: 10.1086/698958

You can download the published version at:

https://doi.org/10.1086/698958 


\title{
Revamping the Metaphysics of Ethnobiological Classification
}

Final version forthcoming in Current Anthropology

\section{David Ludwig}

Wageningen University and Research Knowledge, Technology and Innovation Group Hollandseweg 1, $6706 \mathrm{KN}$ Wageningen david.ludwig@wur.nl

\begin{abstract}
Ethnobiology has a long tradition of metaphysical debates about the "naturalness," "objectivity", "reality", and "universality" of classifications. Especially the work of Brent Berlin has been influential in developing a "convergence metaphysics" that explains cross-cultural similarities of knowledge systems through shared recognition of objective discontinuities in nature. Despite its influence on the development of the field, convergence metaphysics has largely fallen out of favor as contemporary ethnobiologists tend to emphasize the locality and diversity of classificatory practices. The aim of this article is twofold: First, I provide a historical account of the rise and fall of convergence metaphysics in ethnobiology. I show how convergence metaphysics emerged as an innovative theoretical program in the wake of the "cognitive revolution" and the "modern evolutionary synthesis" but failed to incorporate both theoretical insights and political concerns that gained prominence in the 1980s and 1990s. Second, I develop a positive proposal of how to engage with metaphysical issues in ethnobiology. By integrating traditional research on convergence of classifications with more nuanced accounts of distinctly local categories, a revamped metaphysics of ethnobiological classification can make substantial contributions to debates about ontological difference in anthropology and about the relation between applied and theoretical ethnobiology.
\end{abstract}

Ethnobiology of the 1960 s and 1970 s was deeply steeped in a metaphysical discourse about "discontinuities in nature" (Hunn 1977) and "the structure of nature itself" (Berlin et al. 1966, 275). For example, Diamond (1966) influentially argued that correspondence between ethnotaxa "and species as recognized by European taxonomists reflects the objective reality 
of the gaps separating sympatric species." Bulmer $(1970,1087)$ suggested that "the hard core of lower order groupings in any taxonomy [...] simply has to be 'general' or 'natural' and consist of multi-purpose, multi-dimensional units which bear a definite correspondence to those applied by the biological scientist." Berlin $(1973,260)$ argued that "the objective biological discontinuities recognized by primitive man are, for the most part and with explainable exceptions identical at some level with those recognized by western science." Dywer $(1976,440)$ pointed out that "the folk classifier perceives objective discontinuities in the natural world" which ground convergence with biological species that are recognized in contemporary biology.

While Berlin's monograph Ethnobiological Classification (1992) provides a synthesis of this ambitious theoretical program, metaphysical debates about classification have largely vanished from the ethnobiological research literature. In part, this development reflects a broader trend towards questions of application in ethnobiology (e.g. Hanazaki et al. 2013, Hidayati et al. 2015; Nabhan 2016; Wolverton 2013; Wyndham et al. 2011). Insofar as ethnobiologists have become increasingly concerned with issues such as agricultural practices, conservation biology, knowledge rights, environmental justice, and indigenous self-determination, theoretical debates about classification have lost their status as the methodological core of the discipline. However, even current research on classification in ethnobiology largely avoids continuing theoretically ambitious and metaphysical projects. Much of the recent literature on ethnobiological classification focuses on the generation of new data but is remarkably hesitant to use this data for wider theoretical or even explicitly metaphysical arguments (for an exception, see Begossi et al. 2008). Finally, metaphysical claims about converging knowledge systems are occasionally also rejected more directly by arguing that their "over-simplified use of universal principles risks ignoring the very essence of diversity itself. Instead, we must give particular attention to the anomalies, the unique 
cultural expressions, and the collisions of dissonant taxonomic structures" (Nabhan 2016, 27).

The aim of this theoretical essay is twofold. First, I develop a historical analysis of the rise and fall of metaphysical ambitions in ethnobiology. I argue that "convergence metaphysics" emerged in the late 1960s as an innovative theoretical program but failed to respond to both epistemic and political concerns. On the basis of this historical diagnosis, I argue that the failure of convergence metaphysics should not lead to a general rejection of metaphysical considerations and I propose a revamped metaphysics of ethnobiological classification that incorporates insights from debates about taxonomic pluralism. I conclude by arguing that such a revamped metaphysics of ethnobiological classification can provide substantial insights both for anthropological debates about ontological difference and for integrating applied and theoretical concerns in ethnobiology.

\section{The Rise and Fall of Convergence Metaphysics in Ethnobiology}

\section{I.1 The Emergence of Convergence Metaphysics}

Convergence metaphysics in ethnobiology emerged in the late 1960s as an innovative program that synthesized cross-cultural studies of folk biological classification with theoretical developments of the "cognitive revolution" and the "modern evolutionary synthesis". Despite this complex historical constellation, the basic idea of convergence metaphysics can be illustrated with simple examples such as Berlin's $(1992,9)$ informal experiment of bird classification: "Museum skins of several species of brightly colored Amazonian birds [...] are dumped from a basket in a heap on a table. [...] A student volunteer is called from the class and asked to simply 'classify' the collection. The student's efforts always result in a series of neatly stacked groups of individual birds, usually lined up in a 
row. The piles correspond perfectly to the groupings recognized by scientific ornithologists, as well as to those of the Huambisa and Aguaruna Jivaro from whom the specimens were collected." This agreement between untrained students, scientific ornithologists, Huambisa and Aguaruna Jivaro is clearly an interesting phenomenon that requires explanation. At this point, convergence metaphysicians move from empirical claims about classificatory behavior to a metaphysical explanandum: taxonomic convergence can only be explained under the assumption of joint recognition of objective discontinuities in nature.

While the argument is quickly introduced, its influence on the historical development of ethnobiology requires a more complex analysis. Harold Conklin's unpublished dissertation The Relation of Hanunóo Culture to the Plant World (1954) is widely hailed as a watershed moment in the development of ethnobiology. Conklin's work was groundbreaking both in its methodological sophistication and its detailed documentation of "more than 1800 mutually exclusive folk taxa, while botanists divide the same flora - in terms of species - into less than 1300 taxa" $(1962,12)$. Conklin's study did not only exemplify a new "ethnoscientific" program (e.g. Frake 1962; Sturtevant 1964; Werner 1966) in anthropology but also provided a model for countless studies of ethnobiological classification that followed in the 1960s and 1970s. One may be tempted to argue that this influx of new data was already sufficient to push the young field of ethnobiology towards convergence metaphysics: as researchers returned from different parts of the world with stunningly similar accounts of taxonomic systems, their metaphysical explanation in terms of objective discontinuities in nature was an inevitable consequence.

Indeed, Berlin's $(1992,13)$ recollection of encountering Conklin's work illustrates this assumption: "One October morning, after having spent several months of ethnobiological fieldwork in Chiapas, [...] I was pleasantly surprised to receive in the mail a dog-eared xeroxed copy of 'The Relation of Hanunóo Culture to the Plant World'". What impressed Berlin was not only Conklin's detailed documentation of Hanunóo classifications but rather 
the similarity between the taxa that are recognized by Hanunóo in the Philippines and Tzeltal in Chiapas: "I was suddenly confronted with an unlikely problem in culture history: transpacific ethnobotanical contact between the Philippines and southern Mexico, direction of transmission not yet determinable!' (Berlin 1992, 13, emphasis in original). Of course, Berlin did not actually assume that there was transpacific contact between Hanunóo and Tzeltal but rather concluded that they employ similar taxonomies because they recognize the same objective biological structures.

However, it would be inadequate to explain the rise of convergence metaphysics solely as a reaction to novel data. In fact, much of the early ethnoscientific literature insisted on cross-cultural relativity rather than convergence. Sturtevant's 1964 review of the ethnoscientific literature illustrates this point by arguing that "work in this field [ethnobiology] is partially relevant, in that it has frequently been realized (although also too often ignored) that the species and genus categorizations of other cultures normally do not coincide with those of Western science" $(1964,120)$. Even Berlin's earliest writings emphasized diversity rather than similarity. In "Folk Taxonomies and Biological Classification", Berlin et al. (1966) found that only 34 percent of Tzeltal plant names corresponded to a botanical species and most of them were assumed to be influenced by western taxonomies through association "with Hispanic culture". Instead of proposing a convergence metaphysics, Berlin et al. (1966) largely interpreted Tzeltal plant classification in terms of unique cultural uses by pointing out the correlation between classificatory detail and cultural significance of ethnotaxa.

What then led to the widespread adoption of convergence metaphysics in works such as Diamond (1966), Berlin et al. (1973), Hunn (1975), and Brown (1977)? Why did Berlin $(1973,7)$ passionately denounce what he called the "relativistic position I once espoused myself"? In addition to the availability of new cross-cultural data, the emergence of convergence metaphysics has to be understood through its embedding in two powerful 
theoretical developments: the search for universal structures in the "cognitive revolution" and the species realism of the "modern evolutionary synthesis".

The crucial importance of linguistics and cognitive psychology for the development of ethnobiology is widely recognized in the literature (see D'Ambrosio 2014; Hunn 2007; Sobra and Albuquerque 2016) and the prominence of convergence metaphysics cannot be understood independently of debates about universal cognitive structures that dominated the early days of the cognitive revolution. Universalism constituted a core theme in founding documents of the cognitive revolution from Miller's (1956) hypothesis of a general capacity of the human short-term memory to Chomsky's (1965) universal grammar. Anthropologists who joined this young movement in the context of an "ethnoscientific" program often aimed for analogous insights about general rules and structures below the "surface" of cultural diversity. For example, Casagrande $(1963,280)$ argued that anthropologists and linguists share "the task of uncovering the common pattern, or the universal design, that underlies the exuberant variety of the particular configurations that we call cultures and languages." Convergence metaphysics would have been hardly possible without these universalistic ambitions that ethnobiologists shared with their peers in linguistics and psychology: instead of emphasizing the diversity of perspectives on the biological world, cognitive ethnobiology aimed at identifying underlying structures of convergence in classificatory systems.

While the influence of the cognitive revolution on the development of ethnobiology is widely acknowledged, the emergence of convergence metaphysics is equally indebted to a second theoretical development: species realism in the context of the "modern evolutionary synthesis". Evolutionary biology had often been interpreted as challenging realism about biological taxa with authors like Burma (1949) arguing that continuous lines of descent can only be divided arbitrarily and therefore expose species as "a mental construct without objective existence" $(1949,369)$. Mayr's (1949) realist response to Burma is illuminating in several ways: First, his observation of a "striking discontinuity between local populations" 
$(1949,371)$ became the core evidence for the compatibility of population biology and species realism that also found advocates in other influential proponents of the modern synthesis like Dobzhansky (1963) and Simpson (1951). As Mayr put it in a later formulation of his realist paradigm: "One of the minor tragedies in the history of biology has been the assumption [...] that constancy and clear definition of species are strictly correlated and that one must either believe in evolution (the 'inconstancy' of species) and then have to deny the existence of species except as purely subjective, arbitrary figments of the imagination or, as most early naturalists have done, believe in the sharp delimitation of species but think that this necessitates denying evolution" $(1957,2)$.

Second, Mayr's influential arguments for species realism often relied on casual remarks about the convergence of folk classifications and modern biology. In his 1949 exchange with Burma, for example, Mayr writes that the "primitive Papuan of the mountains of New Guinea recognizes as species exactly the same natural units that are called species by the museum ornithologist" $(1949,371)$. In a later publication, Mayr $(1963,17)$ remarks: "I spent several months with a tribe of superb woodsmen and hunters in the Arfak Mountains of New Guinea. They had 136 different vernacular names for the 137 species of birds that occurred in the area, confusing only two species. It is not pure coincidence that these primitive woodsmen arrive at the same conclusion as the museum taxonomists, but an indication that both groups of observers deal with the same non-arbitrary discontinuities of nature". While many of these comments are made en passant, Mayr's influence on ethnobiology is directly acknowledged in Diamond's classical argument that "one-to-one correspondence [between Fore and scientific bird taxa] strikingly illustrates the objective reality of the species" $(1966,151)$. In fact, Diamond's publication was largely framed as a replication of Mayr's findings. And even in Berlin's 1992 book Ethnobiological Classification, Mayr still stands out as the scientific authority for a species realism that acknowledges "discrete, discontinuous chunks of biological reality" (Berlin 1992, 81). 
To sum up, the rise of convergence metaphysics in ethnobiology in the late 1960s was the result of at least three interacting factors: (1) new data about folk classification of unprecedented detail as pioneered by Conklin (1954); (2) the emphasis of universal cognitive structures in the early waves of the cognitive revolution such as Miller (1956) and Chomsky (1965); (3) the consolidation of species realism in the writings of Mayr (e.g. 1949, 1963) and other proponents of the modern synthesis. Building on these developments, convergence metaphysics in ethnobiology established itself as a highly productive research program that employed cutting edge methods from different disciplines and captured the zeitgeist of both the human and the life sciences. Through the 1970s, ethnobiologists used these methods to generate innovative research such as Berlin et al.'s (1973) general principles, Hunn's (1975) measure of degrees of classificatory correspondence, and Brown's (1977) arguments for universal "life forms". The original character of this research not only contributed to the institutionalization of ethnobiology as a field with a distinct identity but also to making ethnobiology a "major powerhouse of [...] cultural-anthropological theory and method" (Anderson 2011, 6).

\section{I.2 Where Things Went Wrong}

The rapid rise of convergence metaphysics through the 1970 s was followed by an almost equally rapid decline. Various critical voices appeared in the 1980 s and by the time Berlin published his synthesizing Ethnobiological Classification (1992) much of the field had already given up on his strong metaphysical program. This is not to say that all aspects of Berlin's framework have fallen out of favor. On the contrary, Berlin's research has set methodological standards of continuing relevance for research on ethnobiological classification (e.g. Cardoso et al. 2010; Lampman 2007; Ferreira et al. 2009; Zariquiey 2014) and some of his theoretical assumptions about taxonomic structures have been widely 
accepted (e.g. Alves et al 2016; Ellen 2006, 6-8; Hunn and Brown 2011). In contrast, Berlin's metaphysical picture of "objective discontinuities in nature" that ground cross-cultural convergence in classifications has largely vanished from the research literature.

In this section, I want to argue that the quick fall of convergence metaphysics has to be understood through two parallel developments that exploited different weaknesses. First, convergence metaphysics relied on the combination of rather different theoretical frameworks: the assumption of universal cognitive structures in the human sciences and species realism in the biological sciences. This combination became increasingly unstable as several researchers used assumptions about universal cognitive structures to explain cross-cultural convergence without any reference to the traditional species realism. Second, the emphasis of convergence became increasingly controversial as cognitive ethnobiology became challenged by projects that focused on local classifications and local ecological knowledge of indigenous communities. These two parallel developments left convergence metaphysics with a quickly dwindling number of allies. While cognitively oriented researchers abandoned metaphysical claims about species realism in favor of a more austere cognitive science of classification, large parts of the ethnobiology community shifted emphasis from cross-cultural convergence to the diversity of "local" and "traditional ecological knowledge".

\section{The Crumbling Alliance Between Cognitive Universalism and Biological Realism:} Convergence metaphysicians commonly start with observations about cross-cultural similarities in classifications and argue that the these similarities can only be explained in terms of joint recognition of objective discontinuities in nature. While the cognitive sciences turned out to be a reliable ally in making the case for cross-cultural convergence, it became increasingly clear in the 1980 s that a consequent cognitivism can provide explanations of convergence that actually compete with traditional species realism. To put it terms of a somewhat simplified slogan: converging classifications can be the result of shared cognitive 
biases rather than shared recognition of objective joints in nature. For example, a taxon such as "tree" is found in many different cultures but one may argue that this tells us much more about our evolved perceptual systems than about "objective joints in nature". As Atran put it as early as 1981: "How comes it that cultures belonging to such widely separated times and places invariably produce similar basic groupings? The only conceivable answer is that they employ identical cognitive processing over similar empirical domains" (64).

Atran's work since the 1980s clearly illustrates the tensions between traditional convergence metaphysics and research that was increasing entangled with cognitive psychology of classifications and mental representations. Atran's Cognitive Foundations of Natural History (1990) develops a sophisticated cognitivist alternative to convergence metaphysics by proposing an account of phenomenally coherent folk kinds that do not have to converge on scientific kinds. As Atran argues, categories such as "bug", "butterfly", "hawk", "thistle", "tree", or "sparrow" commonly converge between folk-taxonomies even if they do not correspond to any categories in scientific taxonomies. In explicit contrast with Berlin's insistence that "in any local flora or fauna a single pattern stands out from the rest" (1992, 9), Atran argued that different patterns will stand out for folk biologists and for scientists who classify populations on the basis of phylogenetic relations.

In an important sense, Atran's arguments did not only turn the cognitivist orientation but also the insights of the modern evolutionary synthesis against convergence metaphysics. Insofar as contemporary scientific taxonomies reflect phylogenetic relations rather than morphological similarities, they will often lead to diverging taxonomic distinctions. As Atran points out in his review of Berlin's Ethnobiological Classification, convergence can therefore be a symptom of taxonomies that do not adhere to phylogenetic standards: "Should the correlation between the cultural consensus on folk taxonomy and classical taxonomy prove stronger [than with phylogenetic taxa], then continued preference for classical taxonomy may 
reflect the continuing hold of common sense on science rather than a strictly 'objective' correspondence" (Atran 1993, 197).

The Epistemic and Political Importance of Local Knowledge: Atran's critique is remarkable because of its internal character that turned assumptions about universal cognitive processing and about biological taxonomy against the program of convergence metaphysics. While this critique exposed internal tensions within cognitive ethnobiology, a largely parallel development in ethnobiology challenged the priority of cognitive considerations and its focus on cross-cultural convergence.

Hunn's article on "the utilitarian factor in folk biological classification" (1982) provides an early and highly influential expression of doubts about the dominance of cognitive perspectives in ethnobiology. Partly reflecting on his own writings from the 1970s, Hunn argued that "we have unduly stressed the disinterested intellectualism of our informants, and as a consequence have taken for granted their practical wisdom. Pragmatism is no sin" (1982, 831). By reconsidering utilitarian explanations, Hunn proposed a model of taxonomic convergences that emphasized questions of practical value and therefore differed not only from Berlin's universally recognized natural kinds but also from Atran's cognitively unified folk taxa.

While the cognitive and cultural foundations of life form taxa such as "tree" became the subject of a specialized controversy within ethnobiology (e.g. Hunn 1987; Atran 1987), Hunn's comments also captured a more general discontent (see also Dougherty 1978; Ellen 1986; Silitoe 1980) with the state of cognitive ethnobiology that eventually contributed to the widespread adoption of novel frameworks such as "traditional ecological knowledge" (TEK) in the late 1980s and early 1990s (e.g. Johannes 1989; Berkes et al. 1995). Of course, it had always been recognized that cross-cultural similarities between ethnobiological knowledge had to be understood on the background of cultural diversity and local expertise about 
environments. For convergence metaphysicians, however, the most important task of ethnobiology was to figure out what knowledge systems had in common and not to analyze in what ways they were unique. TEK shifted priorities in a rather dramatic way by emphasizing the importance of distinctly local forms of knowledge about specific environments. Given this reconsideration of "utilitarian factors" and local knowledge, a growing number of ethnobiologists also stressed the importance of phenomena that were neglected in convergence metaphysics as peripheral exceptions and "special purpose taxa".

While the increased recognition of TEK shifted attention to local forms of knowledge, many of these more specific challenges overlapped with a more general hostility towards universalist projects in cultural anthropology. Partly motivated by Geertz' $(1973,11)$ famous critique of the ethnoscientific tradition, ethnobiology of the late 20th century increasingly found itself in heated controversies about postmodernism and poststructuralism in anthropology (see Anderson 2000; Hunn 2007). Much of this literature did not only challenge the epistemological foundations but also the political implications of projects that focused on convergence and complementarity. For example, Nadasdy $(1999,7)$ influentially argued that integration projects will often lead to a marginalization of knowledge that does not meet the criteria of scientists and resource managers: "whole aspects of aboriginal peoples' reality fall outside the established categories of scientific resource management".

In the context of ethnobiological classification, the most bitter controversies developed around Berlin's ethnopharmacological research in the late 1990s and the formation of the "International Cooperative Biodiversity Group“ in Chiapas. Following the general program of convergence metaphysics, Berlin assumed that Maya knowledge about pharmacological properties of plants would turn out to be largely commensurable with western science and could be used for mutual benefit (Berlin and Berlin 1996). Anthropologists like Nigh $(2000,452)$ did not only challenge the theoretical assumptions of 
convergence metaphysics but rather accused Berlin's program of doing "violence to indigenous meanings of nature, medicine, and property."

One may wonder whether any of the mentioned challenges is sufficient for a rejection of the entire program of convergence metaphysics. Surely, there seems to be a lot of room for compromise. For example, one could acknowledge Atran's (1990) points about the phenomenal basis of folk taxa such as "tree" while pointing out that other folk taxa such as "jaguar" continue to converge on scientific taxa. Surely, one could continue to treat cross-cultural convergence as an important issue in ethnobiology without denying the importance of cross-cultural divergence and without marginalizing distinctly local forms of TEK. And indeed, there were serious and methodologically sophisticated attempts to find a compromise. Ellen (1986), for example, proposed a model for the integration of cognitive and social factors in ethnobiological classification and concluded that "at once the debate between universalists and relativists is seen as the caricature it inevitably must be; an entirely false opposition sustained through ideological mystification and polemic“ $(1986,93)$.

Berlin (1992), however, was not having any of it. Responding to Ellen's suggestion that the contrast between universalists and relativists is an unhelpful caricature, Berlin insisted that "the debate, both in anthropology in general and ethnobiology in particular, is hardly a caricature" $(1992,11)$. While universalists followed "biological systematists who hold that biological species are real," $(1992,12)$ Berlin argued that the relativist tradition in anthropology had become lost in postmodernist fashions. For Berlin, there remained a choice between two incompatible options: species are either recognized or rejected as objective natural kinds. Any attempt to come up with a compromise is going to blur this contrast between two irreconcilable metaphysical perspectives. Interestingly, the same attitude is found simultaneously in the writings of Mary Douglas as one of the main proponents of the relativist tradition. Discussing the contrast between ethnoscientific and 
constructionist approaches in anthropology, Douglas warned about an "eclectic muddle" and continued by arguing that "nature cannot provide the basis of classification systems; there are no natural kinds, or if there are, biological species cannot be included" $(1993,161$; see also Ellen 2006, 2).

\section{Rethinking Metaphysics of Ethnobiological Classification}

The rise and fall of convergence metaphysics in the second half of the 20th century is not merely a topic of historical interest but continues to have a profound impact on the state of ethnobiological research. Given the increasingly ideological stalemate towards the end of the 20th century, it is not surprising that ethnobiologists have become largely disengaged with the entire debate about the metaphysics of ethnobiological classification. As Zent $(2009,27)$ remarks: The debate about "intellectualist against utilitarian explanations of the prolific classification abilities of folk peoples [...] has faded from active academic discussions without any clear resolution." Zent's observation is not only apt for the internal debates in ethnobiology but also affects their wider position in contemporary anthropology. While controversies about the metaphysics of ethnobiological classification were carried out in journals of general anthropology such as the American Anthropologist (Berlin et al 1973; Brown 1977; Hunn 1982) and Current Anthropology (Brown 1985; Atran 1993; Nigh 2002), the topic has largely disappeared from active discussion.

The aim of the following sections is two-fold. First, I argue that the general demise of metaphysical debates about ethnobiological classification reflects a number of missed opportunities of connecting ethnobiology with the more recent development of debates about taxonomies and ontologies. The problem is not metaphysics of ethnobiological classification in general. The problem is that the metaphysical debates became stuck in a polemic of universalism vs. relativism that isolated it from theoretical developments in other fields. 
Second, I argue that a revamped metaphysics of ethnobiological classification can provide important insights for debates in anthropological theory and for attempts to connect applied and theoretical debates in ethnobiology.

\section{II.1 Three Missed Opportunities}

While metaphysical debates in ethnobiology became increasingly stagnant in the late 20th century, innovative theoretical frameworks were developed in a number of fields from biological systematics and philosophy of science to social ontology and anthropological theory. In the following, I want to highlight three theoretical developments that have been largely missed in the ethnobiological literature and show how their incorporation can lead to a nuanced framework beyond controversies between universalism and relativism.

1. Pluralism: From the perspective of current debates about biological taxonomies, one of the most striking features of convergence metaphysics is its uncompromising monism. According to Berlin, there is exactly one fundamental and objective way of carving up biological diversity at the species level. As he put it in Ethnobiological Classification: "in any local flora or fauna a single pattern stands out from the rest" (1992, 9). Although Berlin acknowledges the abstract possibility of classifying biological diversity in different ways, he quickly adds that "the empirical comparative data between Western scientific and folk scientific systems of biological classification, as well as among the folk systems themselves, point to a single, preferred ordering that is primary and fundamental in humans' appreciation of nature's plan" and concludes that "one way is more natural than any other" (Berlin 1992, 26).

While this monism reflects classical articulations of species realism by authors like Mayr, it strongly contrasts with the pluralist mainstream that has emerged from decades of debate 
about the "species problem" (e.g. Ereshefsky 2001; Slater 2013; Zachos 2016). Pluralists in the species debate often accept metaphysical claims about "discontinuities in nature" but emphasize that biological discontinuities come in different dimensions. Kitcher's (1984) classical defense of species pluralism, for example, starts with the observation that synchronic and diachronic discontinuities do not always align. For example, morphological and phylogenetic classifications of organisms will overlap but often also lead to slightly different boundaries of taxa. Furthermore, both synchronic and diachronic perspectives can be grounded in different discontinuities. It is not only the case that there are different (e.g. morphological or genetics) sets of synchronic properties but also that diachronic classification allows the formulation of different species concepts. At what point does a lineage constitute a new species? It has become widely acknowledged that traditional answers such as Mayr's "biological species concept" will not always be applicable and that well-known alternatives such as Van Valen's (1977) "ecological species concept" and Cracraft's (1983) "phylogenetic species concept" will be at least occasionally preferable. Of course, the status and extent of species pluralism remains debated in the light of an ever-growing number of candidate definitions (e.g. Zachos 2016). However, it has become widely accepted that contemporary biology uncovers biological discontinuities along related but not always co-extensional dimensions. Even if we restrict ourselves to contemporary academic taxonomy, it is therefore often not the case that "a single pattern stands out from the rest" and this result needs to be considered by anyone who is interested in biological classification across cultural contexts.

2. Realism: Convergence metaphysicians may suspect that this new pluralist mainstream only illustrates the spurious influence of relativism in biological taxonomy. However, this would be a mistake. Pluralism is not relativism. On the contrary, much of the pluralist literature explicitly endorses realist positions and even employs the same metaphysical metaphors of "discontinuities" "patterns", and "clusters" that dominate the classical literature 
on ethnobiological classification. Instead of endorsing relativist doctrines, pluralists typically embrace the realist idea that taxonomies reflect empirical knowledge about discontinuities in nature. However, they add that there are many more discontinuities to be found than imagined by traditional monistic doctrines. Given this plurality of discontinuities, any classification of the natural world will have to prioritize certain aspects on the basis of the interests of a scientific discipline or community.

What is at stake in many current debates about pluralism is not relativism but rather the extent of classificatory flexibility in taxonomies. Dupré's (1993) "promiscuous realism" has taken a radical stance in extending pluralist realism to everyday entities such as "culinary kinds" that are distinguished by gastronomic properties even if they are not reflected in scientific taxonomies. Dupré's reasoning is both decisively metaphysical and realist: A distinction between culinary kinds is not merely conventional and it is certainly not based on a misunderstanding of the natural world. Instead it is based on the recognition of specific gastronomic properties. While these properties may not matter in the context of phylogenetic classifications of organisms, they are not only relevant for the gastronomic purposes but also perfectly real.

Not everyone assumes that such a promiscuous realism is sufficient for addressing classificatory practices in biology. For example, Boyd's influential account of natural kinds in terms of homeostatic properties (e.g. Boyd 1999, see also Wilson et al. 2007) is more restrictive than Dupré's "promiscuous realism" as it assumes a cluster of (e.g. behavioral, ecological, genetic, morphological, phylogenetic) properties that are unified through homeostatic mechanisms. Property clustering is supposed to capture the observation that scientific kinds tend to differ from Dupré's "gastronomic kinds" in supporting a large variety of inferences. Other authors have modified Boyd's proposal by dropping the requirement of homeostatic mechanisms (Slater 2015) or providing a more general account of the causes of property clustering (Khalidi 2015). However, none of the mentioned authors wants to turn the 
clock back to monism or to relativism. Instead, the question is how to understand the scope of pluralism in the interplay between empirically discovered structures and contingent classificatory interests (Ludwig forthcoming).

3. Norms of Classification: Pluralism can often be understood as a metaphysical claim about a multiplicity of patterns or clusters that undermines the ideal of one privileged system of "joints in nature". At the same time, taxonomic pluralism typically also involves the epistemological thesis that successful science requires the recognition of different discontinuities for different purposes (e.g. Magnus 2012). In the context of the species debate, for example, Kitcher (1984) argues that different scientific projects require different species concepts. For example, paleontologists will find the biological species concept unsatisfying if there is no data that could verify that the central criterion of interbreeding. Other cases do not reflect the epistemic position of the researcher but the characteristics of target populations: while a zoologist like Mayr will find that the biological species concept often generates plausible taxonomies, the situation is different for a botanist who researches plant species that commonly hybridize (Van Valen 1977) or a microbiologist who is concerned with organisms that do not even reproduce sexually (O'Malley 2014).

Much of the classical pluralist literature emphasizes the diversity of epistemic interests in biology that require focus on biological discontinuities along different dimensions. More recently, however, there has also been increased attention towards more pragmatic and social considerations that can guide the choice of taxonomic frameworks (Ludwig 2016a). For example, consider that phylogenetic species concepts will often split traditional taxa into several new species. Groves and Grubb's Ungulate Taxonomy (2011) illustrates this implication by doubling the number of bovid species. In a recent commentary, Zachos and Lovari $(2013,144)$ do not only mobilize epistemic but also normative conservation concerns in their rejection of the phylogenetic species concept in mammalian zoology: "Unwarranted 
splitting [...] has a number of deleterious consequences because it reduces the population size of each species with concomitant legal and regulatory ramifications. Genetic rescue may not be allowed (because it would require the crossing of two different acknowledged species!), and as a result, the increase in genetic drift and inbreeding and the decrease in fitness may not be counteracted."

While debates about pluralism are occasionally recognized in ethnobiology (e.g. Souza and Begossi 2007; Si 2016), the ethnobiological literature has become largely disconnected from the development of wider theoretical debates about taxonomies. This situation has led to a number of missed opportunities for reconfiguring metaphysical debates about ethnobiological classification beyond the traditional contrast between universalism and relativism. One of the most persisting problems of convergence metaphysics is that it seems to neglect or even marginalize classifications that do not converge on modern biology. If "one way is more natural than any other" (Berlin 1992, 26), ethnotaxa will either convergence on scientific taxa or be defective as representations of the natural world. A pluralist approach, however, implies that convergence cannot be a necessary criterion for taking ethnotaxa seriously. If taxonomies in contemporary biological systematics do not converge on each other, we should also not require that ethnobiological classifications converge towards one fundamental taxonomy.

While pluralism limits reliance on convergence in ethnobiology, its realist components also create an important contrast with relativism (Ludwig 2016b). First, recall that most pluralists are comfortable with realist appeals to patterns and clusters of properties that ground taxonomic practices. Even if two taxonomies fail to converge, they may still both allow a realist interpretation in the sense that they simply reflect different empirically discovered clusters of properties. Second, realist interpretations of pluralism also provide the necessary resources for more nuanced interpretations of complex convergence-divergence 
patterns. In some cases, communities with different interests will identify different clusters of properties in their taxonomies. In other cases, we should expect taxonomic convergence because different communities will recognize the same patterns. For example, consider convergence between indigenous societies of the Americas as well as contemporary biologists in recognizing jaguars as a distinct taxon. Pluralists do not have to deny that taxonomic convergence occurs when a population such as jaguars is clearly distinct from all other populations along all relevant criteria (Ludwig 2016c). In the case of jaguars, it does not matter whether we rely on behavioral, ecological, genetic, morphological, or phylogenetic criteria because jaguars are clearly distinct from other Felidae in the Americas along all of these criteria.

Finally, debates about taxonomic pluralism also provide resources for rethinking the role of "utilitarian" concerns in ethnobiology. While Hunn influentially argued that practical concerns had been treated "almost as an embarrassment" $(1982,831)$ in ethnobiology, the traditional framework of convergence metaphysics provided a clear motivation for this attitude: if ethnotaxa are supposed to "carve nature at its joints" in an objective manner, they cannot be "distorted" by the idiosyncratic concerns and priorities of local communities. Recent debates about the norms of classification in scientific practice amount to direct inversion of this situation as it is widely acknowledged that "utilitarian" concerns about practical significance and even social implications shape the structure of scientific taxonomies. For example, recall the case of the phylogenetic species concept and the doubling of bovid species in comparison to more traditional species concepts (Groves and Grubb 2011). One may debate whether Zachos and Lovari's (2013) concerns about "taxonomic inflation" and negative conservation effects are legitimate but there is no completely neutral position for evaluating the options independently of any concerns.

\section{II.2 Why Metaphysics of Ethnobiological Classification Matters}


In the last section, I argued that ethnobiology largely missed the opportunity to engage with the development of theoretical debates about taxonomies that followed the decline of the classical program of convergence metaphysics since the 1990s. While this creates an opportunity for reconsidering the metaphysics of ethnobiological classification, one may doubt that there is a lot to gain from such a project. Does ethnobiology really need a metaphysics of classification? Hasn't ethnobiology moved beyond this issue? In the following, I want to sketch two benefits from taking metaphysical issues seriously. First, they provide resources for reintroducing ethnobiological classification as a relevant topic for core debates in anthropological theory. Second, metaphysics of ethnobiological classification can build important bridges between applied and theoretical issues in contemporary ethnobiology.

\section{II.2.1 Anthropological Theory and Ontological Difference}

The classical debate about convergence metaphysics developed in the center of anthropological theory. Not only did the debate unfold in journals such as American Anthropologist and Current Anthropology but the issues at stake related to the wider theoretical questions such as the relation between cognitive and constructivist approaches in anthropology. The demise of convergence metaphysics in recent decades has not only affected the visibility of theory in ethnobiology but also the visibility of ethnobiology in anthropological theory. The most obvious illustration for this development are controversies about an "ontological turn" that have captured much of the attention of anthropological theory. While large parts of this ontological literature are concerned with broadly "ethnobiological" issues of indigenous understanding of animals, plants, and environments (e.g. Descola 2013; Kohn 2013; Viveiros de Castro 2014), ethnobiology in the 
institutionalized sense has played at best a marginal role in the development of these debates (however, see Anderson 2015; Ellen 2016, Daly et al. 2016, Rival 2016 for engagement from ethnobiological perspectives).

If research on ethnobiological classification is framed in terms of Berlin's assumption of a "single pattern [that] stands out from the rest" $(1992,9)$, it directly contradicts recent anthropological claims about ontological difference and alterity. While pluralist accounts of taxonomies in the sense of section II.1 promise more common ground, my point here is not simply that a pluralist metaphysics of ethnobiological classification could be assimilated into the "ontological turn". Instead, research on ethnobiological classification provides a vast body of empirical evidence that can lead to novel perspectives on ontological difference. Rather than simply repeating core claims from the ontological turn, a revamped metaphysics of ethnobiological classification could provide complementary and innovative insights that build on more fine-grained forms of divergence in biological ontologies.

To illustrate this potential of ethnobiological contributions to current debates with at least one example, consider the common criticism (e.g. Laidlaw and Heywood 2013, Vigh and Sausdal 2014) of the ontological turn as facing a dilemma of either describing or making ontological claims. If anthropologists merely describe the ontological commitments of different societies, they hardly engage in a novel project that indicates any "turn" whatsoever. If anthropologists endorse the ontologies they describe, however, they run into danger of a relativist metaphysics "which mistakes multiple representations of the world for multiple worlds" (Henare et al. 2007,10). While ontologically oriented anthropologists have proposed different responses to this dilemma (e.g. Holbraad and Pedersen 2017), a pluralist metaphysics of ethnobiological classification clearly rejects the first horn of merely describing ontological assumptions. The whole point of a substantial metaphysical pluralism is to argue for the legitimacy of multiple frameworks in engaging with biological diversity. 
While a pluralist metaphysics of ethnobiological classification clearly moves beyond a mere description of classificatory plurality, it also avoids the second horn of an excessive relativism of multiple worlds. On the contrary, I have argued that pluralism about biological ontologies is commonly integrated with a realist picture. Differences between biological ontologies are not suspicious cases of "worldmaking" (Goodman 1978) but are explained through the many different patterns and clusters that can be detected in the biological domain. A taxonomy that is driven by concerns and values of a local community will often identify different patterns than found in the taxonomy of a western zoologist. For example, a local indigenous community may classify a group of organisms partly on the basis of ecological and even social relations while a scientist may focus on cladistic relations. As a result, they recognize different connections between organisms and end up with different ontologies.

Of course, it is far from trivial to generalize such a strategy from fine grained ontological differences in ethnobiology (e.g. what counts as a bird?) to more fundamental ontological disagreements (e.g. what counts as a person?) that have dominated controversies about the ontological turn. However, ethnobiology can provide an interesting addition to ontological debates in anthropology through its "bottom-up" strategy that starts with often very specific forms of disagreement such as the extension of an individual taxon. Tackling methodological problems on this level can provide resources for addressing more fundamental forms of divergence in the cross-cultural comparison of ontologies.

\section{II.2.2 Bridging Applied and Theoretical Ethnobiology}

Revamping the metaphysics of ethnobiological classification can contribute to a better understanding of the relevance of ethnobiology for anthropological theory and especially for debates about ontological difference. However, there are also more direct benefits for 
ethnobiological practice. More specifically, a reconsideration of metaphysical issues can help to bridge divisions between applied research that has developed from debates about of traditional ecological knowledge (TEK) and theoretical issues that have been tackled in cognitive and in linguistic traditions of ethnobiology.

In recent years, it has become common to describe ethnobiology as having entered an "age of application" (Wolverton et al. 2014) and many ethnobiologists embrace this development as a necessary step for engaging with pressing questions of environmental justice and "the needs of a world coping with rapid ecological change and shifting political economies" (Wyndham et al. 2011, 124; see also Sillitoe 2006; Wolverton et al. 2014). Many ethnobiologists would agree that this emphasis of applied significance should not be played off against theoretical issues in ethnobiology and that "there is no fundamental conflict between seeing human knowledge as intellectually satisfying and at the same time useful" (Hunn 2014, 147; see also Nazarea 1999).

Despite sophisticated integrative approaches that bring together cognitive ethnobiology and TEK (e.g. Zent and Maffie 2009), there can also be little doubt that ethnobiological research often remains divided along general methodological lines. The emphasis of convergence in the cognitivist tradition and divergence in anthropological discussions of alterity provides a straightforward illustration of this persisting danger to "fragment an already small body of scholars" (Wolverton 2013, 21).

A pluralist metaphysics of ethnobiological classification provides resources to build bridges between methodological traditions by integrating concerns about locality and classification. In a pluralist framework, the local structures of TEK are of crucial relevance for ethnobiological classification. In order to understand not only convergence but also divergence of taxonomies, ethnobiologists have to engage with patterns and regularities that matter for local practices even if they are not of interest for western taxonomists. While this research on patterns of local significance has been largely conducted in the context of TEK, 
it becomes indispensable for making sense of diverging taxonomic decisions of different communities. Furthermore, this situation also makes ethnobiological classification relevant for research on the applied dimensions of TEK. Insofar as taxonomies are shaped by local expertise and priorities, they become expressions and repositories of local knowledge. One important source for the analysis of TEK is therefore the analysis of local taxonomies.

To illustrate this general argument with a brief example, consider Alcántara-Salinas et al.'s (2016) recent discussion of Zapotec classifications of birds in San Miguel Tiltepec, Oaxaca. The northern Zapotec language of San Miguel Tiltepec does not include an ethnotaxon with an extension similar to the phylogenetic group of Aves. Vigini comes closest as it includes 109 of the 209 recognized bird species but is restricted by several criteria such as size that exclude both unusually small (e.g. hummingbirds) and large (e.g. hawks) Aves. Furthermore, Alcántara-Salinas et al. identify four larger taxonomic groups that partly overlap with vigini: (1) Artaba rhela refers to nocturnal birds that include "omen birds, which make noises during the night believed to forewarn people of impending ill-fortune" (Alcántara-Salinas et al 2016, 666). (2) Bëa gishi refers to terrestrial birds and those with limited flight such as roadrunners and turkeys. (3) Lurshba Includes often large and predatory birds that fly in the open sky such as vultures and hawks. (4) Rshbaa includes flying birds that are common in villages and fields and therefore have special relations to communities.

Neither convergence metaphysics nor classificatory relativism seem to provide attractive frameworks for engaging with such complex cases of local classificatory systems. From the orthodox perspective of convergence metaphysics, higher bird taxa of Zapotec in San Miguel Tiltepec simply fail to carve nature at its joints. As such, they seem of only secondary importance compared to other ethnotaxa (e.g. more specific bird generics) that do converge on modern biological systematics. From an orthodox relativist perspective, it does not make sense to claim that this Zapotec classification fails to carve nature at its joints but it 
is also difficult to see how this classificatory system could reflect unique knowledge about the structure of a local ecosystem. Instead, it seems that Zapotec classifications of birds in San Miguel Tiltepe are just one of countless possible and equally valid constructions of arbitrary linguistic divisions between organisms. A pluralist metaphysics of ethnobiological classification allows a different perspective that asks how TEK is incorporated in this unique classificatory practice. As such, theoretical understanding of Zapotec taxonomies of birds requires careful engagement with Zapotec TEK. Furthermore, understanding of Zapotec TEK requires careful engagement with these unique taxonomies as expressions and repositories of local Zapotec knowledge. Instead of treating applied questions about TEK and theoretical questions about classification as separate research programs, a pluralist metaphysics of ethnobiological classification can help to integrate them as complementary dimensions of ethnobiological research.

\section{Conclusion}

In contrast with the dynamic development of applied ethnobiology, debates about the metaphysics of ethnobiological classification have been largely in the doldrums since the 1990s. While there have been innovative contributions by various authors (e.g. Atran and Medin 2010; Ellen 2016; Newmaster et al. 2007), the field as a whole has largely retracted from metaphysical debates about ethnobiological classification. The aim of this article has been to argue that it is both possible and fruitful to revamp these debates with more recent methodological tools that have been developed in the context of taxonomic pluralism. Engaging with these general questions is not only epistemically intriguing but can help to clarify the contributions of ethnobiology to anthropological debates about ontological difference and to strengthen the relations between applied and theoretical research in ethnobiology. 


\section{References}

Alcántara-Salinas, Graciela, Roy F. Ellen, and Jaime E. Rivera-Hernández. 2016. Ecological and Behavioral Characteristics in Grouping Zapotec Bird Categories in San Miguel Tiltepec, Oaxaca, Mexico. Journal of Ethnobiology 36.3: 658-682.

Anderson, Eugene. 2011. Ethnobiology: Overview of a Growing Field. In Ethnobiology, edited by Eeugene Anderson, 1-14. New York: Wiley.

—_. 2015. Review: Beyond Nature and Culture Ethnobiology Letters 6(1):208-211.

Atran, Scott. 1981. Natural Classification. Social Science Information 20(1):37-91.

—_ 1987. The Essence of Folkbiology. American Anthropologist 89 1):149-51.

—_ 1990. Cognitive Foundations of Natural History. Cambridge: Cambridge University Press.

—_. 1993. Folk Biological Cognition. Current Anthropology 34(2): 195-97.

Atran, Scott, and Douglas Medin. 2010. The Native Mind and the Cultural Construction of Nature. Cambridge: MIT Press.

Begossi, Alpina, Mariana Clauzet, J. L. Figueiredo, Luziana Garuana, R. V. Lima, Priscila F. Lopes, Milena Ramires, Andréa L. Silva, and Renato AM Silvano. 2008. Are Biological Species and Higher-Ranking Categories Real? Current Anthropology 49(2): 291-306.

Berkes, Fikret, Carl Folke, and Madhav Gadgil. 1995. Traditional Ecological Knowledge, Biodiversity, Resilience and Sustainability. In Biodiversity Conservation, 281-99. Springer.

Berlin, Brent. 1973. Folk Systematics in Relation to Biological Classification and Nomenclature. Annual Review of Ecology and Systematics 4(1):259-71.

—_. 1992. Ethnobiological Classification. Princeton: Princeton University Press. 
Berlin, Elois Ann, and Brent Berlin. 1996. Medical Ethnobiology of the Highland Maya of Chiapas, Mexico. Princeton: Princeton University Press.

Berlin, Brent, Dennis Breedlove, and Peter Raven. 1966. Folk Taxonomies and Biological Classification. Science 154(3746): 273-75.

—_ 1973. General Principles of Classification and Nomenclature in Folk Biology. American Anthropologist 75(1):214-42.

Boyd, Richard. 1999. Homeostasis, Species, and Higher Taxa. Species: New Interdisciplinary Essays, 141-85, Cambridge: MIT Press.

Brown, Cecil. 1977. Folk Botanical Life-Forms: Their Universality and Growth. American Anthropologist 79(2): 317-42.

— 1986. The Growth of Ethnobiological Nomenclature. Current Anthropology 27(1):1-19.

Bulmer, Ralph. 1970. Which Came First, the Chicken or the Egg-Head. In Echanges et Communications. The Hague: Mouton.

Burma, Benjamin. 1949. The Species Concept: A Semantic Review. Evolution 3: 369-73. Cardoso, Domingos B. O. S., Luciano P. de Queiroz, Fábio P. Bandeira, and Aristóteles Góes-Neto. 2010. Correlations Between Indigenous Brazilian Folk Classifications of Fungi and Their Systematics. Journal of Ethnobiology 30 (2): 252-64.

Casagrande, Joseph. 1962. Language Universals in Anthropological Perspective. Universals of Language, 220-35, Cambridge: MIT Press.

Chomsky, Noam. 1965. Syntactic Structures. Paris: Mouton.

Conklin, Harold. 1954. The Relation of Hanunóo Culture to the Plant World. New Haven: Dissertation Yale University.

_ 1962. Lexicographical Treatment of Folk Taxonomies. In Readings in the Sociology of Language, The Hague: Mouton. 
Cracraft, Joel. 1983. Species Concepts and Speciation Analysis. Current Ornithology 1(4):159-87.

D’Ambrosio, Ugo. 2014. Theoretical Reflections on Ethnobiology in the Third Millennium. Contributions to Science, 10(1):49-64.

Daly, Lewis, et al. 2016. "Integrating Ontology into Ethnobotanical Research." Journal of Ethnobiology 36.1: 1-9.

Descola, Philippe. 2013. Beyond Nature and Culture. Chicago: University of Chicago Press.

Diamond, Jared. 1966. Zoological Classification System of a Primitive People. Science 151(3714):1102.

Dobzhansky, Theodosius. 1963. Species in Drosophila. In Proceedings of the Linnean Society of London, 174:1-12.

Dougherty, Janet. 1978. Salience and relativity in classification. American ethnologist $5(1): 66-80$.

Douglas, M. 1993. Hunting the Pangolin. Man 28 (1): 161-65.

Dupré, John. 1993. The Disorder of Things. Cambridge: Harvard University Press.

Dwyer, Peter D. 1976. An Analysis of Rofaifo Mammal Taxonomy. American Ethnologist 3(3):425-45.

Ellen, Roy 1986. Ethnobiology, Cognition and the Structure of Prehension. Journal of Ethnobiology 6(1):83-98.

__ 2006. The Categorical Impulse. New York: Berghahn Books.

_.2016. Is There a Role for Ontologies in Understanding Plant Knowledge Systems? Journal of Ethnobiology 36 (1): 10-28.

Ereshefsky, Mark. 2001. The Poverty of the Linnaean Hierarchy. Cambridge University Press.

Ferreira, Emmanoela N., José da S Mourão, Pollyana D. Rocha, Douglas M. Nascimento, and Dandara Monalisa Mariz da SQ Bezerra. 2009. Folk classification of the crabs and 
swimming crabs (Crustacea-Brachyura) of the Mamanguape river estuary, Northeastern-Brazil. Journal of ethnobiology and ethnomedicine 5(1_: 22.

Frake, Charles. 1962. The Ethnographic Study of Cognitive Systems. In T. Gladwin and W. Sturtevant, eds. Anthropology and Human Behavior, 72-85, Washington, D.C.: Anthropological Society of Washington.

Geertz, Clifford. 1973. The Interpretation of Cultures: Selected Essays. New York: Basic. Goodman, Nelson. 1978. Ways of Worldmaking. New York: Hackett Publishing.

Groves, Colin, and Peter Grubb. 2011. Ungulate Taxonomy. JHU Press.

Hanazaki, Natalia, Elaine Mitie Nakaruma, Bianca Lindner, and Walter Simon De Boef.

2013. Opportunities for Ethnobotany to Contribute to Community Biodiversity Management. In Community biodiversity management, edited by Walter Simon De Boef et al., 141-45. London: Routledge.

Henare, Amiria, Martin Holbraad, and Sari Wastell. 2007. Thinking through Things. London: Routledge.

Hidayati, Syafitri, Merlin Franco, and Rainer W. Bussmann. 2015. Ready for phase 5-current status of ethnobiology in Southeast Asia. Journal of ethnobiology and ethnomedicine 11(1): 17.

Holbraad, Martin, and Morten Axel Pedersen. 2017. The Ontological Turn. Cambridge: Cambridge University Press.

Hunn, Eugene. 1975. A Measure of the Degree of Correspondence of Folk to Scientific Biological Classification. American Ethnologist 2 (2): 309-27.

__ 1977. Tzeltal Folk Zoology New York: Academic Press.

—_. 1982. The Utilitarian Factor in Folk Biological Classification. American Anthropologist 84(4): 830-47.

—_. 1987.Reply to Atran. American Anthropologist 89:147-49.

—. 2007. Ethnobiology in Four Phases. Journal of Ethnobiology 27(1):1-10. 
2014. To Know Them Is to Love Them. Ethnobiology Letters 5:146-50.

Hunn, Eugene, and Cecil Brown.Linguistic ethnobiology. In Ethnobiology, edited by Eugende Anderson, 319-333. New York: Wiley.

Johannes, Robert. 1989. Traditional Ecological Knowledge. IUCN.

Khalidi, Muhammad Ali. 2015. Natural Kinds as Nodes in Causal Networks. Synthese, online first, $1-18$.

Kitcher, Philip. 1984. Species. Philosophy of Science, 51(2):308-33.

Kohn, Eduardo. 2013. How Forests Think. Berkeley: University of California Press.

Lampman, Aaron. 2007. General principles of Ethnomycological classification among the Tzeltal Maya of Chiapas, Mexico. Journal of Ethnobiology, 27(1): 11-27.

Laidlaw, James, and Paolo Heywood. 2013. One More Turn and You're There. Anthropology of This Century 7. http://aotcpress.com/articles/turn/.

Ludwig, David. 2016a. Ontological choices and the value-free ideal. Erkenntnis 81.6:1253-1272.

- 2016b. The Objectivity of Local Knowledge: Lessons From Ethnobiology. Synthese, online first.

—_. 2016c. Overlapping Ontologies and Indigenous Knowledge. From Integration to

Ontological Self-Determination. Studies in History and Philosophy of Science Part A 59:36-45.

__ forthcoming. Letting go of "Natural Kind". Towards a Multidimensional Framework of Non-Arbitrary Classification. Philosophy of Science.

Magnus, P. D. 2012. From Planets to Mallards Basingstoke: Palgrave Macmillan.

Mayr, Ernst. 1949. The Species Concept: Semantics versus Semantics. Evolution 3 (4): $371-73$.

- 1957. Species Concepts and Definitions. In The Species Problem, 371-88. New

York: Arno Press.

. 1963. Animal Species and Evolution. Oxford: Oxford University Press. 
Miller, George A. 1956. The Magical Number Seven, plus or Minus Two. Psychological Review 63 (2):81-97.

Nabhan, Gary Paul. 2016. Ethnobiology for the Future. Tucson: University of Arizona Press. Nadasdy, Paul. 1999. The Politics of TEK: Power and the“ Integration' of Knowledge. Arctic Anthropology, 36(1):1-18.

Nazarea, Virginia D. 1999. Ethnoecology: situated knowledge/located lives. Tucson: University of Arizona Press.

Newmaster, Steven G., Ragupathy Subramanyam, Nirmala C. Balasubramaniyam, and Rebecca F. Ivanoff. 2007. The Multi-Mechanistic Taxonomy of the Irulas in Tamil Nadu, South India. Journal of Ethnobiology 27 (2): 233-55.

Nigh, Ronald. 2002. Maya Medicine in the Biological Gaze. Current Anthropology 43 (3): $451-77$.

O’Malley, Maureen. 2014. Philosophy of Microbiology. Cambridge: Cambridge University Press.

Rival, Laura. 2016. "Botanical Ontologies Special Section of the Journal of Ethnobiology Post-Face”. Journal of Ethnobiology 36(1): 147-149.

Si, Aung. 2016. The Traditional Ecological Knowledge of the Solega. Dordrecht: Springer.

Sillitoe, Paul. 1980. Confusions in the Classifications. Ethnos 45 (3-4): 133-56.

—_. 2006. Ethnobiology and Applied Anthropology. Journal of the Royal Anthropological Institute 12 (s1): S119-42.

Simpson, George Gaylord. 1951. The Species Concept. Evolution 5 (4): 285-98.

Slater, Matthew 2013. Are Species Real?: An Essay on the Metaphysics of Species. Basingstoke: Palgrave Macmillan.

__ 2015. Natural Kindness. The British Journal for the Philosophy of Science $66(2): 375-411$. 
Sobral, André, and Ulysses Paulino Albuquerque. 2016. History of Ethnobiology. In Introduction to Ethnobiology, 9-14. Dordrecht: Springer.

Souza, Shirley, and Alpina Begossi. 2007. Whales, Dolphins or Fishes? Journal of Ethnobiology and Ethnomedicine 3(1.

Sturtevant, William. 1964. Studies in Ethnoscience. American Anthropologist 66(3):99-131.

Valen, Leigh Van. 1977. Ecological Species, Multispecies, and Oaks. Taxon 25(2/3):233-39.

Vigh, Henrik Erdman, and David Brehm Sausdal. 2014.From essence back to existence: Anthropology beyond the ontological turn. Anthropological Theory 14(1):49-73.

Viveiros de Castro, Eduardo. 2014. Cannibal Metaphysics. Minneapolis, MN: Univocal Publishing.

Werner, Oswald. 1966. Pragmatics and ethnoscience. Anthropological linguistics 8(8):42-65.

Wilson, Robert, Matthew Barker, and Ingo Brigandt. 2007. When Traditional Essentialism Fails: Biological Natural Kinds. Philosophical Topics 35(1/2):189-215.

Wolverton, Steve. 2013. Ethnobiology 5: Interdisciplinarity in an Era of Rapid Environmental Change. Ethnobiology Letters 4:21-25.

Wolverton, Steve, Justin Nolan, and Waquar Ahmed. 2014. Ethnobiology, Political Ecology, and Conservation. Journal of Ethnobiology 34(2):125-152.

Wyndham, Felice, Dana Lepofsky, and Sara Tiffany. 2011. Taking Stock in Ethnobiology Journal of Ethnobiology 31(1):110-27.

Zachos, Frank, and Sandro Lovari. 2013. Taxonomic Inflation and the Poverty of the Phylogenetic Species Concept. Hystrix, the Italian Journal of Mammalogy 24(2):142-44.

Zariquiey, Roberto. 2014. Name Types, Polysemy and Contrast Sets in Kakataibo Ethnobiological Nomenclature (Pano, Peru). Journal of Ethnobiology 34(2): 251-272.

Zent, Stanford. 2009. A Genealogy of Scientific Representations of Indigenous Knowledge. Landscape, Process and Power, 19-67, New York: Berghahn Books. 
Zent, Stanford and Maffi Luisa. 2009. Final report on indicator No. 2: methodology for developing a vitality index of traditional environmental knowledge (VITEK) for the project Global Indicators of the Status and Trends of Linguistic Diversity and Traditional Knowledge. Canada: Terralingua. 